\title{
Narrando la diáspora indígena a través de la cámara de Yolanda Cruz
}

\author{
Narrating the indigenous diaspora through Yolanda Crus's lens \\ Argelia González Hurtado 1 (iD) \\ St. Mary's College of Maryland (Estados Unidos)
}

acceso $\partial$ abierto

Para citaciones:

González, A. (2020). Narrando la diáspora indígena a través de la cámara de Yolanda Cruz. Visitas al Patio, 14(2), 86-99. DOI: 10.32997/RVP-vol.14-num.2-2020-2781

Recibido: 15 de febrero de 2020

Aprobado: 20 de junio de 2020

Editor: Silvia Valero. Universidad de Cartagena-Colombia.

Copyright: (C) 2020. González, A. Este es un artículo de acceso abierto, distribuido bajo los términos de la licencia https://creativecommons.org/licenses/by-nc$\underline{\mathrm{sa} / 4.0 /}$ la cual permite el uso sin restricciones, distribución y reproducción en cualquier medio, siempre y cuando el original, el autor $y$ la fuente sean acreditados.

\section{RESUMEN}

El artículo explora las primeras obras documentales de la cineasta chatina Yolanda Cruz: Guenati'zá, The Ones Who Come to Visit (2004) y Sueños binacionales/Bi-National Dreams (2005). El análisis de estos documentales se centra en las estrategias cinematográficas que Cruz utiliza para representar la migración indígena de los pueblos de Oaxaca a los Estados Unidos. Se arguye que estos documentales revelan una noción de identidad basada en actos de autodefinición, un proceso activo y constante de elección y posicionamiento, moldeado por las experiencias de migración.

Palabras clave: activismo político y cultural; documental; medios indígenas; México; migración; video indígena; Yolanda Cruz.

\begin{abstract}
The article explores the first documentary works of Chatina filmmaker Yolanda Cruz: Guenati'á, The Ones Who Come to Visit (2004) and Sueños binacionales/Bi-National Dreams (2005). The analysis of these documentaries focuses on the cinematographic strategies that Cruz uses to represent the indigenous migration of the communities of Oaxaca to the United States. These documentaries, it is argued, reveal a notion of identity based on acts of self-definition, an active and constant process of choice and positioning, shaped by migration experiences.
\end{abstract}

Key words: documentary; Indigenous media; Indigenous video; Mexico, migration; political and cultural activism; Yolanda Cruz.

\footnotetext{
${ }^{1}$ Doctora en Spanish and Latin American Studies de Alberta University. Profesora Asistente de Español y Estudios Latinoamericanos en St. Mary's College of Maryland, Department of International Languages and Cultures. agonzalezhurtado@smcm.edu
} 
El narrar las vivencias dentro de un marco de migración es un tema recurrente en las producciones de los creadores audiovisuales indígenas contemporáneos en México, lo cual no es extraño ya que los movimientos migratorios no son un fenómeno nuevo. En lo que hoy se conoce como México, el movimiento de los pueblos indígenas tiene siglos de historia como lo muestra, por ejemplo, La tira de la Peregrinación en donde se narra el peregrinaje del pueblo mexica de su territorio de origen, la mítica Aztlán, al valle de Anáhuac en el que fundaron Tenochtitlán (Torres y Carrasco 2008:10). Los realizadores indígenas contemporáneos han capturado diversos movimientos migratorios tanto al interior del país como al exterior. Sin embargo, desde la década de los noventa del siglo pasado los trabajos audiovisuales se han enfocado en la migración de comunidades indígenas a Estados Unidos. Esto debido al crecimiento exponencial de emigrantes a ese país como respuesta al empeoramiento de las condiciones económicas y sociales causadas, entre otros factores, por las políticas neoliberales. Como ya ha sido estudiado por académicos como Homi Bhabha (Locations of Culture), Stuart Hall ("New Ethnicities") y Néstor García Canclini (Culturas Híbridas), entre otros, la migración es un fenómeno que se presta para la construcción de "nuevos discursos" ya que los individuos que migran están en constante construcción y reconstrucción de su identidad. Es decir, el migrante vive en un espacio intersticial (in-between), tomando prestado el concepto de Bhabha, que no es ni su lugar de procedencia ni el lugar donde se ha establecido sino un sitio donde hay una constante negociación construyendo nuevas narrativas identitarias que le ayudan a dar dirección a su "nueva" realidad. Así, los videastas indígenas en México que narran la migración entretejen en sus trabajos el discurso étnico con otros discursos identitarios que son forjados por ésta.

Bajo este contexto, el propósito de este trabajo es analizar las primeras obras documentales de la cineasta chatina Yolanda Cruz ${ }^{2}$. Me enfoco en las estrategias cinematográficas que Cruz utiliza para representar la diáspora indígena de los pueblos de Oaxaca como el mixteco ${ }^{3}$, el chatino y el zapoteco ${ }^{4}$. Estos documentales revelan una noción de identidad basada en actos de autodefinición, un proceso activo y constante de elección y posicionamiento, moldeado por las experiencias de migración. En particular me centro en Guenati'zá, The Ones Who Come to Visit (2004) y Suenos binacionales/Bi-National Dreams (2005). Arguyo que las historias que los videastas indígenas diaspóricos, como Cruz, producen son un trabajo de triple autoetnografía ya que además de interpretar su propia cultura (la cultura de origen) y la cultura nacional en la que están inmersos, en este caso la mexicana, también interpretan y traducen para su público el contexto migratorio (González Hurtado, 2017:91-92). Con auto-etnografía me refiero a lo que Mary Louise Pratt define como las formas mediante las cuales el individuo colonizado, o en este caso bajo un contexto hegemónico, se representa a sí mismo activamente utilizando medios propuestos por los grupos en el poder, en este caso las convenciones del documental y lenguaje audiovisual (2008:9).

\footnotetext{
${ }^{2}$ El pueblo chatino es un grupo étnico de México que habita en el suroeste del estado de Oaxaca.

${ }^{3} \mathrm{El}$ pueblo mixteco está asentado en el noreste del estado de Oaxaca. De acuerdo con la Comisión Nacional para el Desarrollo de los Pueblos Indígenas (2003) los mixtecos representan el cuarto pueblo indígena más numeroso en México.

${ }^{4}$ Los zapotecos, llamados también zapotecas, son un pueblo indígena de México que habita principalmente en el estado de Oaxaca. La cultura zapoteca fue en tiempos precolombinos una de las más importantes de Mesoamérica.
} 
Al mismo tiempo, discuto que los comunicadores indígenas no solo realizan un trabajo etnográfico, sino que, como lo ha señalado Freya Schiwy, al tomar prestados elementos ajenos a su cultura como las tecnologías audiovisuales e integrarlas a sus tradiciones están indianizando los medios. Es decir, realizan un proceso de apropiación de los medios para sus propios fines, los cuales se encuentran arraigados en la comunidad indígena (2009: 12). De esta manera, al indianizar los medios y llevar a cabo un triple trabajo auto-etnográfico se muestra la complejidad cultural desde la cual los realizadores indígenas crean sus historias que se intersectan con discursos étnico, nacional y transnacional, así como de género, lingüístico y político; se incluyen elementos distintivos de sus culturas como narrativas orales, iconografías y elementos expresivos como la música, la danza y los rituales; y se apropian de un lenguaje y convenciones audiovisual creadas fuera de sus tradiciones. Indianizar las tecnologías de comunicación representa un proceso complejo de colaboración en varios niveles (entrenamiento, coproducción, financiamientos) entre comunidades indígenas y no indígenas, que complica el concepto de medios indígenas. Esto aunado a la complejidad que presenta la propia definición del concepto indígena.

\section{Definiendo conceptos y situando la obra de Yolanda Cruz}

De acuerdo con el antropólogo Arturo Warman se puede decir que las identidades son vagas y las identidades étnicas, como la indígena, son las más elusivas ya que no tienen un único y nítido signo distintivo porque son múltiples al estar compuestas por varios elementos sin que ninguno sea regular o principal. Además, establece que "las identidades étnicas son fluidas, inasibles y hasta confusas" mostrando una flexibilidad elusiva que explica su transformación y recreación constante (2003:16). Particularmente, Warman señala que en los tres siglos de dominación colonial en México las culturas indígenas se recrearon constantemente, conservando "algo de lo de antes pero no todo" ya que adoptaron e incorporaron mucho de lo nuevo que introdujeron los españoles, pero no todo (2003:25). De esta manera, el autor subraya que pensar en las poblaciones indígenas como una continuidad de lo antiguo es dejar de reconocer la "vitalidad de su creación cultural" e indentitaria que han desarrollado a través del tiempo. Al respecto, Guillermo de la Peña comenta que la noción indígena debe entenderse principalmente como una identidad asumida en la que es necesario pensar en lo indígena como "un concepto análogo, no unívoco ni equívoco, donde pueden darse distintas combinaciones de componentes para distintas situaciones.” (2000:25) En este sentido, se puede decir que lo indígena está ligado a una categoría étnica precolombina que ha ido sufriendo transformaciones y que se caracteriza por estar en constante construcción y negociación con otras categorías identitarias.

En el caso de Yolanda Cruz su historia personal es un claro ejemplo de una identidad indígena fluida y que incorpora otras categorías identitarias a medida que su realidad cambia. Cruz es originaria de Cieneguilla, un pequeño pueblo chatino de Oaxaca, México. Se muda a la capital del estado, la Ciudad de Oaxaca, y después emigra a Estados Unidos. Su entrenamiento como cineasta lo obtuvo al estudiar una maestría en Dirección de la escuela de Cine y Televisión de la Universidad de California en Los Ángeles (UCLA). Al preguntársele por su identidad y la manera en que se concibe por el hecho de hablar tres lenguas (chatino, español e inglés) Cruz esboza las categorías que ha incorporado a su repertorio identitario dependiendo en distintos momentos de su vida: 


\begin{abstract}
Cuando me mudé a la ciudad de Oaxaca, era indígena. Luego, cuando llegué a Estados Unidos, era latina, mexicana. Y ahora, cuando vuelvo a México, soy chatina, y cuando voy a Europa, soy una inmigrante. Abrazo todas las etiquetas. Creo que es muy importante reconocer que la gente ha luchado mucho por sus identidades. Pero más que nada, me consideraría una cineasta indígena. (ChávezGarcía, 2011: 60)
\end{abstract}

Queda claro que Cruz se concibe chatina, indígena, mexicana, latina, inmigrante y estas identidades son reflejadas (explícita o tácitamente) en su obra a través de las historias que presenta como realizadora indígena, identidad a la que concede un lugar primordial.

Por otro lado, es importante contextualizar el trabajo de Cruz como realizadora indígena dentro de la discusión académica sobre lo que son los medios indígenas como el cine y video. De una manera amplia y vaga se puede considerar como medio indígena a todo producto mediático que ha sido conceptualizado o producido por grupos o autores indígenas. No obstante, como señala Richard Pace, esta definición ha generado cierta discusión sobre qué umbral de indigeneidad debe incorporarse en una producción para ser considerada como indígena. Pace señala que esto es particularmente problemático "cuando se lidia con producciones que toman prestados sustancialmente de géneros y convenciones cinemáticas / representacionales no indígenas, así como producciones colaborativas creadas con realizadores de medios no indígenas" (2018:20). Este es el caso de Cruz, quien ha tenido acceso al manejo de códigos y convenciones cinematográficas y que ha incorporado este entrenamiento en sus producciones. Definiciones más refinadas señalan que las producciones mediáticas indígenas deben estar enraizadas estética y culturalmente en la comunidad al representar relaciones sociales dentro de estas (Ginsburg,1994); estas relaciones deben ser representadas con un punto de vista desde adentro de la cultura (Córdova y Salazar, 2008); o bien los realizadores deben estar física y culturalmente enraizados en la comunidad, aunque las producciones sigan las convenciones estéticas hegemónicas (Wortham 2013). En este sentido, las obras de Cruz se encuentran enraizadas tanto en la comunidad indígena migrante en Estados Unidos como en las comunidades en Oaxaca, y presentan un punto de vista interno al ser la realizadora parte de ambas. Cruz señala que:

\footnotetext{
Me convertí en parte de un grupo de oaxaqueños que vivían en Los Ángeles, más como individuo que como cineasta. Para mi tesis, elegí hacer un documental sobre un activista comunitario de Oaxaca, un hombre tan apasionado por su comunidad que gastó cinco años de sus ahorros personales para regresar a su pueblo y hacer una ofrenda (Chávez-García, 2011:58)
}

En cuanto al entorno de video indígena en México, el camino de la realizadora chatina ha sido diferente en varios niveles al de la mayoría de los videastas de este país. Para desarrollar su trabajo la cineasta ha recibido el apoyo de prestigiosas organizaciones como: La Fundación Rockefeller, Latino Public Broadcasting y la Fundación Ford. Además, sus obras han sido exhibidas en festivales y muestras en diferentes países como el Festival de Cine de Sundance o la muestra de Cine Nativo del National Museum of the American Indian. En el 2000, Cruz funda la productora de cine y video Petate Productions con el objetivo de contar historias de los pueblos indígenas. La trayectoria cinematográfica de Cruz ha sido versátil ya que ha realizado cine experimental (Entre sueños, 2000), documental, y recientemente ficción (El reloj, 
2013). ${ }^{5}$ En México el desarrollo del llamado video indígena es, quizá junto con el video en las comunidades Kayapó en Brasil, uno de los casos mejor documentados y estudiados en Latinoamérica. El video indígena fue impulsado principalmente por parte del gobierno al instituir un programa de incorporación de medios en las comunidades indígenas llamado Transferencia de Medios Audiovisuales a Organizaciones y Comunidades Indígenas (TMA). ${ }^{6}$ Posteriormente, con el fin de obtener una mayor autonomía del gobierno, las comunidades indígenas comenzaron a crear sus propios proyectos audiovisuales independientes o con ayuda de organizaciones no gubernamentales nacionales e internacionales. ${ }^{7}$ Desde entonces, la producción de video indígena en México ha sido de las más constantes en Latinoamérica gracias al apoyo de organizaciones gubernamentales y no gubernamentales (Salazar y Córdova, 2008).

Si bien existe una diversidad de formatos en el "video indígena", es el documental el más empleado. Este se caracteriza principalmente por su modo de producción comunitaria y colaborativa donde los sujetos presentados, generalmente, emplean su lengua indígena (Córdova y Zamorano, 2004; Schiwy y Weber, 2017). Sin embargo, como señala Byrt Wammack Weber, el concepto de video indígena en México hace referencia generalmente al estilo de producción promovido por el estado y que desde entonces ha servido de guía para la producción audiovisual indígena (gubernamental y no gubernamental), oscureciendo con esto una genealogía de producciones independientes, colaborativas, comunitarias y de activismo artístico como el "video maya" (2017:16). En este tenor, también han quedado fuera de está genealogía los videastas independientes, las mujeres realizadoras (ya sea colectiva e individualmente), y los realizadores de la diáspora indígena. Así, la cineasta chatina Cruz se ubica en estas categorías: independiente, mujer, y migrante, por lo que su estudio brinda un panorama más amplio de las prácticas mediáticas indígenas en México.

\section{Narrando la diáspora indígena a través de la obra de Yolanda Cruz}

Guenati'zá, The Ones Who Come to Visit, documental de 16 minutos, trata sobre el viaje de regreso a México de Ulises García y su familia para la celebración de las fiestas navideñas en su natal pueblo de Analco en Oaxaca. García, zapoteco, trabaja como jardinero en Los Ángeles, California. En el documental la familia García invita a su viaje a Cruz, quien funge como la narradora. Cruz en su rol de cineasta-etnógrafa aprovecha la experiencia para crear un documental polifónico en el que muestra vistazos a la interacción que los migrantes tienen con su comunidad de origen gracias al retorno temporal de estos por las festividades locales. Así, en este documental se entrelazan las voces de los migrantes, los locales, los jóvenes, los viejos, las mujeres y, desde luego, la de la cineasta.

\footnotetext{
${ }^{5}$ Información disponible en el sitio web de Petate Productions: http://www.petate.com

${ }^{6}$ La participación del gobierno en la promoción del uso del video es un caso especial en Latinoamérica donde éste medio ha sido promovido por organizaciones no gubernamentales principalmente. De acuerdo con M. Elise Marubbio, en Canadá y Estados Unidos, al igual que en México, las primeras iniciativas del cine y video indígena fueron programas gubernamentales. En Canadá, la National Film Board of Canada impulsó a los primeros cineastas nativos por medio del programa Challenge for Change, mientras que en Estados Unidos la National Public Television en colaboración con Native American Public Broadcasting Consortium promovieron el cine y video indígena (2010). ${ }^{7}$ Entre los académicos que han documentado el desarrollo del video indígena en México se encuentran: Antoni Castells-Talens y José M. Ramos Rodríguez (2010), Amalia Córdova y Gabriela Zamorano (1994); Córdova y Juan Francisco Salazar (2008), Alexandra Halkin (2008); Laurel C. Smith (2006, 2008), Wortham (2004, 2005).
} 
Guenati'zá inicia con un primer plano del rostro de un hombre quien dice a la entrevistadora en español: "Mira, yo soy oaxacaliforniano, pero soy de Oaxaca" Inmediatamente después se escucha en voice over una voz de mujer que menciona en inglés "Ulises García is Zapotec, one of the largest indigenous groups in Oaxaca México. Ulises came to Los Angeles in 1982 when he was 18. He has been a gardener and a community organizer". Este comentario se sobrepone a una serie de planos de corta duración, como un plano medio largo y un primer plano que presentan a Ulises en las actividades que desempeña como jardinero. Desde la primera escena, Ulises establece su identidad recreada por su situación de migrante al establecer que se concibe como oaxacaliforniano integrando dos realidades que en su opinión lo definen. La distinción identitaria en este caso está dictada por la geografía en la que Ulises se mueve, cada una con una carga histórica y simbólica particular dentro de sus contextos nacionales. Por ejemplo, Oaxaca es uno de los estados más pobres de México y los grupos indígenas son los más afectados por las condiciones económicas, lo cual es importante porque el estado, junto con Chiapas, es uno de los estados mexicanos con un número importante de indígenas. Oaxaca es hogar de más de 16 grupos indígenas, cada uno con una identidad, idioma y tradiciones distintivos. Mientras que California, antiguo territorio mexicano, es uno de los estados con mayor producto interno bruto en Estados Unidos gracias a la diversificación con actividades económicas en el área de agricultura, turismo, y tecnología e informática, lo que lo hace un punto atractivo para migrantes (nacionales y extranjeros) en buscan mejorar sus condiciones de vida. Aunque ambas regiones han dado un sentido de identidad a Ulises, es su conexión de origen es la que sigue ocupando un lugar primordial al subrayar: "pero soy de Oaxaca".

Después de las primeras imágenes, aparece un plano americano de Ulises con otro individuo en la entrada de un edificio. La narradora continúa: "I met Ulises when he was elected vice-president of FOCOICA which stands for Front of Indigenous Communities of Oaxaca in California, an organization that I also belong to" y al término de esto aparece un plano panorámico que muestra la ciudad de Los Ángeles. Después en un plano general de la ciudad encuadra un conjunto de edificios, lo que da pie a otro comentario de la narradora que señala, "Los Angeles has become home to thousands of oaxaqueños. Most of us have made Los Angeles a home away from home" y simultáneamente da inicio a una pieza musical tradicional oaxaqueña, que queda de fondo sobre imágenes de archivo de la celebración de la "Guelaguetza USA 2002" en Los Ángeles. ${ }^{8}$ El inicio de este documental sirve tanto para que la cineasta se posicione en la narrativa como para presentar la relación que guarda con los sujetos que presenta. Se muestra que Cruz y Ulises no solo son migrantes en Los Ángeles, sino que desempeñan un papel activo entre la comunidad indígena migrante de Oaxaca en esa ciudad. El activismo de ambos, aunque no es explorado en este documental, indica que es una parte importante en el repertorio identitario de ambos. Así, en esta introducción queda asentado que el punto de vista de Cruz es desde el interior de la comunidad como un miembro activo.

\footnotetext{
${ }^{8}$ La Guelaguetza es una celebración tradicional que se lleva a cabo en la capital del Estado de Oaxaca, dedicada a la Virgen del Carmen, aunque sus orígenes se remontan a los tiempos prehispánicos. La celebración se caracteriza por la participación de variados grupos indígenas y folclóricos, donde se distingue el colorido de los trajes típicos que visten los participantes. En el documental vemos que los migrantes han hecho una versión de la celebración en Estados Unidos.
} 
La mayor parte del documental se centra en la interacción de Ulises y su familia con su comunidad de origen. Es en esta interacción en la que Cruz ilustra la manera en que las identidades de los migrantes se han ido trasformando con respecto a las de origen. La realizadora describe el pueblo de Analco como un pueblo casi adormilado que despierta con la llegada de un gran número de migrantes que vuelven en fechas festivas. Por medio de la interacción de los "foráneos" con los "locales" se van revelando las nuevas geografías formadas por la migración. En el plano lingüístico, los pobladores de Analco se comunican en zapoteco, español o inglés. Por ejemplo, los hijos de Ulises, como los otros hijos de migrantes de la comunidad, se comunican en español e inglés, mientras que las personas del pueblo por encima de los 30 años hablan zapoteco y/o español. Cruz muestra cómo se da la interacción en una escena familiar cuando los hijos de Ulises se prueban la ropa que llevarán en las festividades. Usando planos americanos, y con luz ambiental aparece un niño, que es identificado como "Franco, Ulises' nephew" probándose un disfraz con ayuda de la esposa de Ulises y una mujer de edad mayor. Mientras todos hablan en español, Franco expresa en inglés "My mom said I could use my PJs if I get cold", momento durante el cual la mujer de edad mayor solo observa en silencio, lo cual hace pensar que no entendió lo que dijo Franco. En este momento la realizadora, que está fuera de cuadro, pregunta en español “¿Pijamas de qué color?”, y Franco contesta "It's kind'a like brownish white." La realizadora captura la forma en la que el idioma inglés se integra en el reportorio cultural de los migrantes y a la vez deja entrever una posible desconexión con los que no manejan la lengua. Con esto, la cineasta da evidencia el uso de diversos códigos lingüísticos aprendidos por los migrantes en sus zonas de contacto: lengua materna (el zapoteco, chatino, mixteco), el español y el inglés. Este uso de códigos lingüísticos también es representado por la narradora quien, evidentemente para un público anglófono, narra su aventura con los García en inglés y con subtítulos donde el zapoteco o español se hacen presentes. La elección de la narradora se debe a que este documental fue concebido como un proyecto de tesis de maestría para la Universidad de California (University of California, Los Angeles, UCLA) para un público anglófono. De esta manera, Cruz no solo se da a la tarea de analizar la cultura de sus compañeros migrantes, sino que traduce mediante el documental la experiencia migrante-indígena para un público más general, realizando con esto una triple-etnografía.

Como mencioné, en Guenati'zá, The Ones Who Come to Visit las primeras voces que se presentan son la de Ulises y la de Cruz, y poco a poco se incorporan otras como la de la esposa y los hijos de Ulises, la de los familiares de los García y otros habitantes de Analco. Sin embargo, la voz en la que recae el peso del documental es la de la cineasta, en donde establece como base del documental su narración en primera persona. Esta auto-inscripción de Cruz como la de otros cineastas y videastas indígenas, y a diferencia de los realizadores de cine etnográfico o antropológico, se da como realizadora y sujeto a la vez. Con este posicionamiento realizadora-sujeto, Cruz registra su propio discurso identitario que logra con las técnicas documentales que emplea. La cineasta propone un estilo que mezcla los modos de observación y participatorio, en donde esta última no sólo se da con su narración sino también por medio de su interacción con sus sujetos al hacerles preguntas, entrevistándolos, y dejando escuchar su voz en algunos momentos de las entrevistas. Su figura, explícita o tácita, está siempre presente en el documental. Esta corporeidad es por la que abogan algunos cineastas y antropólogos, como David 
MacDougall (1998), para eliminar el mito de un documental objetivo sin "autor". La materialización del cineasta sirve para reconocer su posición y la manera en que participa en la construcción de lo que está representando. La combinación de estilos se presenta en diferentes secuencias. La elección de uno u otro tiene que ver con la forma en que la realizadora se involucra con los sujetos, su cercanía e identificación con éstos. Al mismo tiempo, la mezcla de los modos es una forma de involucrar al espectador con los sujetos. Para explicar esto, analizo dos escenas: la celebración navideña por parte de la comunidad de Analco y la convivencia de las mujeres de la familia de los García en la cocina.

Para ilustrar el festejo navideño de la comunidad, la cineasta emplea el modo observacional en el que la cámara funciona como un instrumento de registro objetivo del evento. Cruz opta por planos lejanos para mostrar la celebración religiosa. El espectador observa a la distancia, tanto el interior como el exterior de la iglesia en la que un fondo musical extra-diegético da unidad al conjunto de planos. Todas las actividades de esta celebración, como el baile y los juegos pirotécnicos, son observados a la distancia. De esta forma, tanto el espectador como Cruz son simples testigos de un rito comunitario al que el espectador ha sido invitado como observador y no como participante. En contraparte, la secuencia que muestra a las mujeres en la cocina charlando y bromeando mientras preparan la cena captura el momento con primeros planos y un montaje dinámico que simulan el vigor de la charla, al tiempo que da registro de parte de la preparación de la cena. La realizadora, fuera de cuadro, hace esporádicas preguntas en voz en off sobre las recetas, mientras la cámara registra la conversación entre las cocineras con planos que subrayan sus gestos y expresiones - primer plano de una mujer riendo, plano conjunto de las mujeres conversando, plano medio de una mujer preparando un pollo y en donde cabe notar que las mujeres conversan en zapoteco y español sin distinción. En esta secuencia, Cruz persigue involucrar al espectador al hacerlo experimentar el momento de distintas formas: con planos de encuadre más cerrado que capturan rostros y expresiones de los sujetos, con la participación de la cineasta al hacer preguntas, y en el acompañamiento en un momento tan cotidiano y personal como lo es una cena-charla durante la víspera de la celebración. De esta manera, la realizadora no solo está cercana a las mujeres sino también acerca al espectador al momento. El uso de estas dos estrategias cinematográficas, observacional y participatoria, manifiesta las formas en que la realizadora se involucra con los sujetos, su cercanía y grado de identificación con éstos. El rito público de la celebración navideña se queda lejano, pero la esfera privada de los sujetos es la que interesa a la realizadora al brindar un punto de vista desde adentro de la cultura.

Si bien en Guenati'₹á se plantea la migración desde un punto de vista doméstico, solo se dan leves vistazos a las reflexiones en torno a la identidad y organización política, en su siguiente producción Sueños binacionales/Bi-National Dreams, Yolanda Cruz profundiza en estos temas.

\section{Activismo y diáspora}

Sueños binacionales/Bi-National Dreams, con una duración de 30 minutos, trata sobre la migración de los mixtecos y chatinos a Estados Unidos y los lazos con la comunidad de origen que se gestan desde la diáspora. El documental se divide en dos partes. En la primera se narran las experiencias de los mixtecos, quienes desde los años setenta se han desplazado a los campos de California estableciendo una red 
de comunicación y organización política y económica con su comunidad en Oaxaca. Mientras que en la segunda parte se muestra la población chatina, a la cual pertenece Cruz. Esta comunidad a diferencia de los mixtecos empezó a migrar a Estados Unidos a partir de los años noventa y, por ende, no cuentan con una organización sólida de ayuda tanto para los que han emigrado como para los que se han quedado en su lugar de origen.

Este documental está construido principalmente por medio de testimoniales, los cuales, como señala MacDougall, son otra manera de comunicar la subjetividad, ya que son los sujetos los que hablan de sus propias experiencias (1998:102). Esta subjetividad se centra en la organización política y el activismo, o la falta de ambos. En el campo literario, el testimonial se define a grandes rasgos como un relato en primera persona que da voz pública a los que por algún motivo viven en los márgenes de una sociedad como las mujeres, los pueblos indígenas y los presos políticos, entre otros. Como señala John Beverly (1987), el narrador del testimonio comunica por medio de su relato una situación que implica cierta urgencia derivada de "una experiencia vivencial de represión, pobreza, explotación, marginalización, crimen, lucha." (Beverly, 1987:9) En el caso de Sueños binacionales, la urgencia surge en la necesidad de organizarse nacional y transnacionalmente para ayudar a los migrantes y a sus familias legal y económicamente.

En Sueños binacionales Cruz, jugando con el prefijo "bi" que forma parte del nombre del documental, busca establecer un juego de contrastes en varios aspectos. El primer contraste se da al mostrar la experiencia migratoria en dos comunidades de Oaxaca: la mixteca, una de las más grandes, y la chatina, una de las más pequeñas. En este documental la realizadora modifica su rol con respecto a Guenati'থá; si en este último Cruz fungió como la narradora y testigo, en Sueños Binacionales su función es como "curadora de voces" al seleccionar a los entrevistados. Esta función es vital para que se transmita la voz del pueblo o en este caso de las comunidades, porque como arguye Margaret Randall "si la historia la hacen los pueblos, una vOz difícilmente puede proyectarla. La voz del pueblo es una voz multitudinaria. [...] A veces una sola persona, por sus características, puede representar a su pueblo" (1992:27). Por lo tanto, Cruz confiere la narración a varias voces, particularmente a cuatro, una voz de un hombre y de una mujer de cada grupo: Rufino Domínguez y Centolia Maldonado por parte de los mixtecos; y Rogelio Cruz y Rosa Cruz por la de los chatinos. Con esto la realizadora expone el punto de vista femenino y masculino, ya que los retos a los que se enfrentan hombres y mujeres, en el marco de la emigración, son distintos. La diferencia entre los testimonios de Rufino y Centolia con los de Rogelio y Rosa es que los dos primeros exponen su experiencia no solo como migrantes sino como activistas políticos y organizadores comunitarios por medio del Frente Indígena de Organizaciones Binacionales (FIOB); mientras que el de los dos últimos se limita a la experiencia de supervivencia cotidiana de un migrante y de sus primeros pasos para formar una organización. A la par de los testimonios principales, Cruz incorpora testimoniales de personas de las comunidades mixteca y chatina en Oaxaca, sobre todo de los ancianos y las mujeres. Con esto se da finalmente otro contraste, el de los que migran y el de los que se quedan en México. 
En cada sección de Sueños binacionales Cruz proporciona información básica de cada grupo étnico. Después de la información inicial sobre la migración mixteca, el primer testimonio que se presenta es el de Centolia. La entrevistada hace un breve resumen sobre las condiciones económicas que han provocado la migración en su región:

Las primeras migraciones de mi familia, las de mis padres, fue a Veracruz porque ahí estaba el corte de la caña. Yo he sido migrante desde muy niña. Mis padres fueron jornaleros agrícolas en los estados de Sinaloa; Baja California, en Mexicali; y en Sonora. Porque aquí no había forma de ganar dinero. El trabajo que hay en la comunidad es para auto-consumo. Nadie te paga el jornal del trabajo que tú estás invirtiendo y como lo vas a vender pues prácticamente nunca tienes dinero.

El testimonio de Centolia sintetiza la problemática que es abordada en el documental de Eduardo Maldonado Jornaleros (1977) sobre la migración nacional de los campesinos debido a la crisis agraria de los años setenta del siglo pasado. Sus padres pertenecen a esa generación de migrantes nacionales conocidos como jornaleros. A décadas de diferencia, Centolia se enfrenta con circunstancias similares. Al igual que ellos, la mujer ha optado por emigrar, sin embargo, no dentro del territorio nacional sino fuera de éste. La situación de urgencia radica en que, al pasar los años, la problemática del campo mexicano y de las comunidades indígenas no ha cambiado de una generación a otra, sino que ha empeorado. La primera intervención de Rufino parece ser una continuación de la de Centolia al hablar de la migración llevada a cabo por su generación: "Mis hermanos, mis primos y acá, me escribían, y bueno, me animaban a venir". Rufino narra las vicisitudes de su peregrinaje a California: desde la decisión de irse; los primeros intentos en pasar la frontera, "no pudimos cruzar la primera vez, se nos terminó el dinero"; las primeras deportaciones, "Cada semana me agarraba la migración, me echaban hasta Mexicali.

El elemento en el que se enfoca Cruz en este documental es el activismo político y cultural que llevan a cabo Centolia y Rufino. Este trabajo es introducido cuando se explica que uno de los primeros programas del FIOB fue un proyecto que involucraba a los pueblos indígenas y a la Asistencia Legal Rural de California para orientar y educar a los trabajadores migrantes sobre sus derechos laborales bajo la ley de California en sus propios idiomas como el mixteco: "Nosotros hablamos un idioma que no es el español ni es el inglés. Hay muchas organizaciones que defienden derechos humanos, derechos de migrantes, pero quien puede hablar el idioma, somos nosotros nada más." A partir de este momento, Rufino Domínguez y Centolia Maldonado cuentan sus experiencias como migrantes y miembros del FIOB.

Aunque la primera parte del documental tiene tintes optimistas, la segunda muestra otra realidad. La sección dedicada a los chatinos en la segunda parte del documental muestra un panorama diferente y con esto deja en claro la disparidad de las "realidades" de migrantes. Ya he mencionado una serie de contrastes que Cruz efectúa entre sección y sección para mostrar que la migración es un fenómeno que es experimentado de manera diferente entre las comunidades que se adhieren a ésta. Lo más notorio con respecto a los chatinos es el tratamiento cinematográfico del testimonio y la forma en que la cineasta se relaciona con los sujetos. Mientras que con los mixtecos Cruz pone el peso en los testimonios de Centolia y Rufino, con 
los chatinos, aunque se introduce a Rosa y Rogelio, el peso narrativo mayor se pone en los habitantes del pueblo de Cieneguilla en Oaxaca.

Después de la información sobre el pueblo chatino, Rosa y Rogelio hablan sobre el trabajo que realizan como recamarera en un hotel y cocinero en un restaurante chino, respectivamente, en Durham, Carolina del Norte. La narración de Rosa se enfoca en ilustrar la supervivencia cotidiana: los sacrificios que hizo para emigrar; el tipo de trabajo que realiza; el costo de la vida en Durham; lo que gana; y la manera en que ayuda a su familia en Cieneguilla. Por su parte, las primeras reflexiones de Rogelio son respecto al contexto de discriminación que ha encontrado en su nuevo entorno, "Muchos blancos ven a los negros como raza inferior [...] La situación de los negros en Estados Unidos es parecida a la situación de los indígenas en México."; y a la vergüenza étnica y lingüística que experimentan los indígenas cuando salen de sus comunidades, "Aquí todavía hay niños que hablan chatino. Pero hay padres que solo enseñan español a sus hijos porque se avergüenzan de su lengua. Pero somos indígenas y no podemos cambiar." Al ejemplificar el contexto lingüístico Rufina subraya las barreras sociales que las comunidades indígenas tienen que vencer tanto en México como al emigrar a Estados Unidos.

La parte de mayor peso narrativo de esta sección, como señalé, son las entrevistas a los ancianos del pueblo, que a manera de testimonio polifónico recoge opiniones que brindan un panorama del sentir de estos sobre la emigración de los habitantes del pueblo. Comentarios como "Antes la gente de acá no sabía nada del norte, pero ahora ya encontraron el camino" o "Las madres jóvenes se van al norte, dejan los niños con la abuela". Los testimonios de los ancianos muestran el desconcierto de la comunidad que se suma a la preocupación de Rosa y a las reflexiones de Rogelio. Este último pone orden al desconcierto: "Estamos lejos de nuestro pueblo, pero no nos olvidamos de donde venimos", comentario que da pie a que Rogelio explique que ante la diáspora de su pueblo decidieron organizarse: "Nuestra misión: mejorar nuestro pueblo." Aunque Cruz no aparece a cuadro en la sección de los chatinos, su participación como parte de este grupo es representada por su papel de entrevistadora, se escucha su voz entrevistando a sus sujetos: ¿Y qué es lo que les hace falta para fortalecer más a su organización?”, pregunta a Rogelio, quien contesta: "Estamos dando pasos lentos". Cruz sigue lanzando preguntas, esta vez a Rosa, "Y ¿tú crees que ahora el pueblo va a estar mejor o peor que antes?" a lo que responde: "En lo económico tal vez, en cuanto a la gente no, pues todos están aquí. Regresaríamos, si supiéramos que hacer". La intervención directa de la realizadora subraya su interés personal por los temas y por aclarar aspectos de estos desde las voces de los migrantes.

Una de las partes más interesantes en el video, y que da nombre al documental, es la idea de identidad que Rufino esboza, en la que él y todos sus compañeros que viven en Estados Unidos son orgullosamente mixtecos, "el orgullo de identidad es lo único que hay en el mundo entero." Sin embargo, señala que se conciben binacionales por vivir y trabajar en Estados Unidos. De hecho, la organización a la que pertenecen resalta en su nombre lo binacional. Así considerarse como binacional es una reflexión que se da en la diáspora, condición que se caracteriza por la insistencia de los individuos no solo por afirmar su identidad "originaria" sino también por ratificar la adquirida en la diáspora. Rufino señala que, al concebirse 
binacionales, el Frente se dio cuenta que debía tener presencia en sus comunidades en Oaxaca, por lo que enviaron a una persona para realizar esta tarea, ya que como indica Centolia: "a veces nos creamos una falsa expectativa de que ir a los Estados Unidos soluciona totalmente el problema económico". Al concebirse binacionales tanto Rufino como Cruz, subrayan solamente una parte de su repertorio identitario que se basa solo en las fronteras nacionales que están cruzando. Esto es de entenderse ya que el FIOB se enfoca en ayudar a los migrantes en un contexto legal y socioeconómico en el marco de ambas naciones. Con esto, Cruz y Rufino soslayan en su discurso político como miembros del Frente la multiplicidad de relaciones histórica, culturales y simbólicas que se intersectan en una experiencia migratoria. Lynn Stephen describe la migración de los pueblos indígenas a los Estados Unidos como una experiencia transfronter (transfronter) y arguye que los migrantes no solo cruzan una frontera nacional sino una gran variedad de fronteras como la étnica, la de género, la generacional, y la regional que moldean la experiencia migratoria (2007:24). Por ejemplo, cada uno de los sujetos migrantes han tenido que cruzar las fronteras étnicas, lingüísticas, y de género tanto en México como en Estados Unidos. Sin embargo, aunque en el marco del documental Rufino, Centolia y la misma Cruz parecen estar más enfocados en promocionar la labor del Frente como una organización binacional, en el discurso más personal estos parecen entender las diferentes fronteras que cruzan. Por ejemplo, en una parte de su testimonio Rufino señala que un mixteco es mexicano, pero es también estadounidense al haber emigrado y estar viviendo en ese lugar.

Sueños binacionales, revela a través de esta serie de testimonios cómo a pesar de las diferencias, tanto mixtecos como chatinos, están conscientes de que una buena parte de la supervivencia de los grupos fuera y dentro de México, depende de la organización y de la demanda del cumplimiento de sus derechos en ambas naciones. Cruz muestra que la organización y el activismo cultural son posibles incluso en un contexto de la migración, en el que es viable abrir espacios de reflexión y análisis de las condiciones que han obligado buscar emigrar a otro país, así como las repercusiones que esta situación tiene en la vida de los individuos directa o indirectamente.

\section{A modo de reflexión final}

La cuestión de la identidad y la representación es una de las prioridades en la agenda de los realizadores indígenas donde éstos muestran la flexibilidad y fluidez de sus identidades, así como la manera en que negocian su autorepresentación cruzando diferentes fronteras. Las categorías incorporadas en los trabajos audiovisuales son en muchos casos tan importantes y fuertes como su identificación étnica. Esto hace eco aún más cuando se discuten las identidades moldeadas por un proceso migratorio, como se explora en el caso de Cruz. De esta manera se observa que el ser, pensarse e imaginarse indígena se entrecruza con el ser, pensarse e imaginarse: mujer, hombre, activista, mexicano, americano, oaxaqueño, mixteco, migrante, videasta, o artista, por ejemplo. Sumando a esto, el uso de los medios de comunicación ha posibilitado a los pueblos indígenas establecer y recuperar la narrativa no solo de su identidad sino de sus historias, en este caso historias de migración.

Como señala Stuart Hall, el activismo cultural se debe a que las experiencias migratorias no son producto de una vida global como recompensa por un estatus, 
educación o poder adquisitivo sino como una vida global impuesta por las disyunciones de la globalización moderna por lo que los individuos desarrollan una consciencia de su condición como migrantes (2008:346-347). En los documentales de Yolanda Cruz se observa además de la toma de consciencia de diferentes grupos de migrantes indígenas, la manera en que los migrantes no sólo continúan los lazos con sus comunidades al reproducir y continuar sus tradiciones y costumbres (como la Guelaguetza o el padrinazgo de las fiestas), sino también la creación de redes con sus comunidades locales por medio, sobre todo, del activismo cultural y político. A través de diferentes estrategias documentales Cruz es capaz representar y traducir el contexto regional, nacional, e internacional en el que están inmersos los migrantes indígenas de diferentes comunidades de Oaxaca. Estos contextos se intersectan como lo muestra Cruz con discursos políticos, de género y simbólicos que muestran la complejidad de la migración.

\section{Bibliografía}

Bengoa, J. (2000). La emergencia indígena en América Latina, México: Fondo de Cultura Económica.

Beverley, J. (2008). Anatomía del testimonio. Revista de Crítica Literaria Latinoamericana, 13(25), 7 16. doi: $10.2307 / 4530303$.

Córdova, A. and Zamorano G. (2004). Mapping Mexican Media: Indigenous and Community Video and Radio. Native Networks, 83-94. Retrieved from http//www.nativenetworks.si.edu/eng/rose/mexico.htm

Cruz, Y. (Director). (2004). Guenati'zá, The Ones Who Come to Visit [Video]. Petate Producciones.

Cruz, Y. (Director). (2009). Reencuentros: 2501 Migrantes [Video]. Petate Producciones.

Cruz, Y. (Director). (2005). Sueños Binacionales [Video]. Petate Producciones.

De la Peña, Guillermo. (2000) ¿Un concepto operativo de lo 'indio’? Estado del desarrollo económico y social de los pueblos indígenas. Primer informe Instituto Nacional Indigenista (pp. 24-25) México: INI-PNUD

González Hurtado, A. (2017). Shaping the Taraspanglish Diaspora. En F. Schiwy y B. Wammack Weber (Eds.), Adjusting the Lens. Community and Collaborative Video in Mexico, (pp 90-118). Pittsburgh: University of Pittsburgh Press.

Halkin, A. (2008). Outside the Indigenous Lens: Zapatistas and Autonomous Videomaking. En P. Wilson y M. Stewart. (Eds.), Global Indigenous Media. Cultures, Poetics and Politics, (pp 160-180). Durham: Duke University Press.

Hall, S. (2008). Cosmopolitanism, Globalisation and Diaspora. Stuart Hall in Conversations with Pnina Werbner. En P. Werbner (Ed.), Anthropology and the New Cosmopolitanism: Roote, Feminist, and Vernacular Perspectives (pp 345-360). Oxford: Berg.

Maldonado, E. (Director). (1977). Jornaleros [Film]. National Film Board.

MacDougall, D. (1998). Transcultural Cinema, Princeton: Princeton University Press.

Millán, M. (1998). Las cajas de Pandora: sobre las imagines creadas por mujeres. En M. Verea y Hierro, G. (Eds.), Las mujeres en América del Norte del fin de milenio, (pp 455-466). México: UNAM.

Pace, R. (Ed.) (2018). From Filmmaker Warriors to -flash Drive Shamans. Indigenous Media Production and Engagement in Latin America. Nashville: Vanderbilt University Press.

Pratt, Mary L. (2008). Imperial Eyes. Travel Writing and Transculturation. London: Routledge.

Ramos Rodríguez, J. and Castells-Talens, A. (2010). The Training of Indigenous Videomakers by the Mexican State: Negotiation, Politics and Media. Post Script, 29(3), 83-94. Disponible en https://www.postscriptjournal.org/

Randall, M. (1992). ¿Qué es y cómo se hace un testimonio? Revista De Crítica Literaria Latinoamericana, 18(36), 23-47. doi:10.2307/4530621 
Salazar, J. F. y Córdova, A. (2008). Imperfect Media and the Poetics of Indigenous Video in Latin America. Indigeneity and Indigenous Media in the Global Stage. En P. Wilson Stewart, M. (Eds.), Global Indigenous Media. Cultures, Poetics and Politics, (pp 39-57). Durham: Duke University Press.

Smith, L. (2006). Mobilizing Indigenous Video: the Mexican Case. Journal of Latin American Geography, (5), 113-128.

Smith, L. (2006). The Search for Well Being. Placing Development with Indigenous Identity. En P. Wilson y M. Stewart. (Eds.), Global Indigenous Media. Cultures, Poetics and Politics, (pp 183-196). Durham: Duke University Press.

Stephen, Lynn (2007). Transborder Lives: Indigenous Oaxacans in Mexico, California, and Oregon. Durham, NC. Duke Universitu Press.

Wammack Weber, B. (2017). (Re)Imagining Diaspora: Two Decades of Video with a Mayan Accent. En F. Schiwy y B. Wammack Weber (Eds.), Adjusting the Lens. Community and Collaborative Video in Mexico (pp 13-38). Pittsburgh: University of Pittsburgh Press.

Warman, Arturo. Los indios mexicanos en el umbral del milenio. México: Fondo de Cultura Económica, 2003.

Wortham, Erica C. (2004). Between the State and Indigenous Autonomy: Unpacking Video Indigena in Mexico. American Anthropologist, 16(2), 364-368.

Wortham, Erica C. (2005). Más allá de la hibridad: los medios televisivos y la producción de identidades indígenas en Oaxaca, México. Liminar. Estudios Sociales y Humanísticos, (3), 34-47. 